\title{
Efeito de subdoses de 2,4-D sal colina na eficiência quântica do fotossistema II do algodoeiro
}

Ricardo Fagundes Marques ${ }^{1}$, Guilherme Henrique Rodrigues Pinheiro ${ }^{1}$, Prissila Pereira dos Santos Araújo ${ }^{1}$, Rodrigo Marques de Souza', Sidnei Roberto de Marchi ${ }^{2}$

${ }^{1}$ Universidade Federal de Goiás - UFG, GO. ${ }^{2}$ Universidade Federal de Mato Grosso - UFMT, MT. E-mail: rfmarques94@gmail.com

\section{Resumo}

Efeitos deletérios de herbicidas ao aparato fotoquímico das plantas podem ser quantificados pelo estudo do potencial de rendimento quântico do fotossistema II (Fv/Fm). Por conta disso, objetivou-se avaliar o efeito de subdoses do herbicida 2,4-D formulação sal colina na eficiência quântica do fotossistema II do algodoeiro em diferentes estádios fenológicos. Foi adotado o delineamento experimental inteiramente casualizado, com sete repetições e os tratamentos foram dispostos por nove subdoses do herbicida 2,4-D formulado com sal colina: 0 (testemunha); 0,$4275 ; 0,855 ; 1,71 ; 3,42 ; 8,55 ; 17,1 ; 34,2$ e 68,4 $\mathrm{g}$ ea ha ${ }^{-1}$ aplicadas nos estádios fenológicos V4 ou B4 do algodoeiro. As plantas foram avaliadas quanto aos sintomas visuais de injúria e a cinética de emissão da fluorescência máxima da clorofila $\alpha(F v / F m)$ aos 3, 7 e 14 dias após a aplicação (DAA) do herbicida. Os valores obtidos foram analisados pelo teste $\mathrm{F}$ e os efeitos dos tratamentos foram comparados pelo teste de Scott-Knott a $5 \%$ de probabilidade. Os dados de injúria visual e $\mathrm{Fv} / \mathrm{Fm}$ foram submetidos à correlação de Pearson. A correlação entre a injúria visual e a $\mathrm{Fv} / \mathrm{Fm}$ nos estádios V4 e B4 é negativa e significativa para ambos os anos de condução do experimento. A variável Fv/Fm não foi afetada pela aplicação de subdoses inferiores a 3,42 $\mathrm{g}_{\text {ea ha }}{ }^{-1}$ de 2,4-D sal colina no estádio V4 e inferiores a $1,71 \mathrm{~g}_{\text {ea }} \mathrm{ha}^{-1}$ no estádio B4 do algodoeiro.

Palavras-chave: auxina sintética; clorofila $\alpha$; fotossíntese; Gossypium hirsutum L.; injúria.

\section{Effect of 2,4-D choline salt subdoses on quantum efficiency of photosystem ii of cotton crop}

\begin{abstract}
Deleterious effects of herbicides on the photochemical apparatus of plants can be quantified by studying the quantum yield potential of photosystem II $(F v / F m)$. Therefore, the objective of this work was to evaluate the effect of subdoses of the herbicide 2,4-D choline salt formulation on the quantum efficiency of the photosystem II of cotton plants at different phenological stages. The study adopted a completely randomized experimental design with seven replications, and the treatments consisted of nine fractions of the average rate indicated on the 2,4-D choline salt herbicide label: 0 (control); $0.4275 ; 0.855 ; 1.71 ; 3.42$; $8.55 ; 17.1 ; 34.2$ and $68.4 \mathrm{~g}_{\text {ae }} \mathrm{ha}^{-1}$ applied at phenological stages V4 or B4 of cotton plants. The plants were evaluated for the visual symptoms of injury and the emission kinetics of maximum chlorophyll a $(F v / F m)$ fluorescence at 3, 7 and 14 days after application (DAA) of the herbicide. The values obtained were analyzed by the $\mathrm{F}$ test and the effects of the treatments were compared by the Scott-Knott test at $5 \%$ probability. The data obtained from visual injury and $\mathrm{Fv} / \mathrm{Fm}$ were also submitted to Pearson's correlation. The correlation between visual injury and $\mathrm{Fv} / \mathrm{Fm}$ in the $\mathrm{V} 4$ and B4 stages is negative and significant for both years of conducting the experiment. The $\mathrm{Fv} / \mathrm{Fm}$ variable was not affected by the application of subdoses lower than $3.42 \mathrm{~g}_{\text {ae }} \mathrm{ha}^{-1}$ of 2,4-D saline choline in the V4 stage and below $1.71 \mathrm{~g}^{2} \mathrm{ha}^{-1}$ in the B4 stage of the cotton plant.
\end{abstract}

Keywords: synthetic auxin; Gossypium hirsutum L.; photosynthesis; injury; chlorophyll $\alpha$. 


\section{Introdução}

O algodoeiro (Gossypium hirsutum L.), pertencente à família Malvaceae, é uma espécie cuja origem está localizada nas Américas do Sul e Central, havendo indícios que possa ter surgido há pelo menos 12,5 milhões de anos (MICHELOTTO et al., 2012; WENDEL et al., 2010).

As condições climáticas favoráveis, a topografia que permite a mecanização da agricultura, os programas governamentais de incentivo e, principalmente, a adoção intensiva de tecnologias modernas são os principais fatores que impulsionaram o cultivo de algodoeiro no Cerrado brasileiro (ZONTA et al., 2014). Todavia, aumentaram-se as preocupações dos cotonicultores devido as possíveis contaminações decorrentes da aplicação de herbicidas nas culturas vizinhas, por conta da liberação antecipada de cultivares de algodoeiro, milho e soja resistentes a herbicidas como o 2,4-D (BYRD et al., 2016).

Segundo Sosnoskie et al. (2015), espécies de plantas geneticamente modificadas resistentes a aplicações de 2,4-D podem fornecer aos produtores uma ferramenta adicional para 0 manejo integrado de espécies de folha larga que apresentam resistência a outras moléculas herbicidas. No entanto, a adoção bem-sucedida desta tecnologia dependerá da capacidade técnica em gerenciar o movimento do herbicida fora do alvo.

O 2,4-D é um herbicida pertencente ao grupo das auxinas sintéticas, também conhecido como mimetizadores de auxinas, que revolucionou o controle de espécies eudicotiledôneas em cereais na década de 1940, sendo o primeiro herbicida seletivo introduzido no mercado com sucesso, e usado até a atualidade (RODRIGUES; ALMEIDA, 2011).

$O$ algodoeiro, no entanto, é considerado como uma das culturas mais sensíveis ao herbicida 2,4-D, sendo que esse herbicida pode causar danos fotossintéticos e sintomas visuais que vão desde malformações e manchas foliares, até epinastia severa e morte das plantas, dependendo das condições ambientais, dose e principalmente do estádio de desenvolvimento no momento da exposição (PETERSON et al., 2016).

Efeitos deletérios de herbicidas ao aparato fotoquímico das plantas podem ser quantificados pelo estudo da fluorescência da clorofila $\alpha$ (FERREIRA et al., 2015). Pesquisas demonstram que as emissões da clorofila $\alpha$ estão intimamente relacionadas com o estado do fotossistema II (BUENASERA et al., 2011), que desempenha papel fundamental no processo de fotossíntese. Em condições de estresse, ocorre o decréscimo da eficiência quântica potencial do fotossistema II, podendo ser detectada pela queda na relação $\mathrm{Fv} / \mathrm{Fm}$ (CRUZ et al., 2009), em que $F v$ representa a fluorescência variável e $F m$ a fluorescência máxima (GONÇALVES et al., 2010).

Por conta disso, o estudo da clorofila $\alpha$ se torna uma ferramenta de análise para investigar possíveis alterações no fotossistema da planta, como resultado de estresses físicos ou químicos, podendo inclusive revelar a presença de substâncias tóxicas amplamente difundidas no meio ambiente, como herbicidas (BUONASERA et al., 2011).

Destaca-se, no entanto, que não existem trabalhos na literatura relacionados aos efeitos do herbicida 2,4-D ao aparato fotossintético do algodoeiro. Sabe-se que plantas de algodoeiro apresentam maior sensibilidade ao herbicida 2,4D quando contaminações ocorrem nos primeiros estádios de desenvolvimento da cultura (MARQUES et al., 2019), uma vez que perdas entre $32 \%$ e $71 \%$ de produtividade podem ser esperadas quando são aplicados doses superiores a $12 \mathrm{~g}$ ea ha ${ }^{-1}$ (EGAN et al., 2014). Essa sensibilidade declina sensivelmente nos estádios reprodutivos, principalmente no início do florescimento, período em que o principal efeito do herbicida reportado é a queda de botões florais (BYRD et al., 2016).

Diante do exposto, o objetivo deste trabalho foi de avaliar o efeito de subdoses do herbicida 2,4-D (sal colina) na eficiência quântica do fotossistema II do algodoeiro em diferentes estádios fenológicos.

\section{Material e Métodos}

Foram realizados dois estudos, conduzidos nos anos de 2018 e 2019, respectivamente, em condições de casa-devegetação na Universidade Federal de Mato Grosso - Campus Universitário do Araguaia, localizado no município de Barra do Garças - MT, cujas coordenadas geográficas são 15-52'29,4" S e $52^{\circ} 18^{\prime} 35,1^{\prime \prime}$ W Gr.

As unidades experimentais foram constituídas por vasos plásticos com capacidade 
de 20,0 L preenchidos com solo classificado como Latossolo Vermelho-Amarelo Distroférrico húmico, o qual foi seco e peneirado. As caraterísticas químicas e físicas deste solo foram: $\mathrm{pH}$ em $\mathrm{CaCl}_{2}$ de 4,4; 70,0 $\mathrm{g} \mathrm{dm}^{-3}$ de matéria orgânica; valores não significativos de $\mathrm{P}$ resina; $\mathrm{V}$ de 9,5\%; e teores de $\mathrm{K}, \mathrm{Ca}, \mathrm{Mg}$ e $\mathrm{H}+\mathrm{AL}$ de 0,21 ;

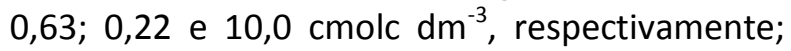
$695 \mathrm{~g} \mathrm{dm}^{-3}$ de areia, $125 \mathrm{~g} \mathrm{dm}^{-3}$ de silte e $180 \mathrm{~g}$ $\mathrm{dm}^{-3}$ de argila. Baseado na análise do solo, as correções de fertilidade e acidez constituíram-se de $3,0 \mathrm{~g} \mathrm{dm}^{-3}$ de calcário dolomítico e $0,35 \mathrm{~g} \mathrm{dm}^{-3}$ de superfosfato simples.
O solo dos vasos manteve-se úmido durante o período experimental através de irrigações automáticas programadas para dispensar quantidades de água próximas à capacidade de campo do respectivo solo. As temperaturas mínimas, máximas e médias diárias no interior da casa-de-vegetação durante os anos de 2018 e 2019 foram obtidas por meio do datalogger da marca Minipa ${ }^{\circledR}$, modelo ezTemp-10 com Certificado de Calibração №. 17688/18, ajustado para realizar uma leitura a cada 30 minutos (Figura 1).

Figura 1. Temperaturas mínimas, máximas e médias ocorridas no interior da casa-de-vegetação durante os anos 2018 (A) e 2019 (B).
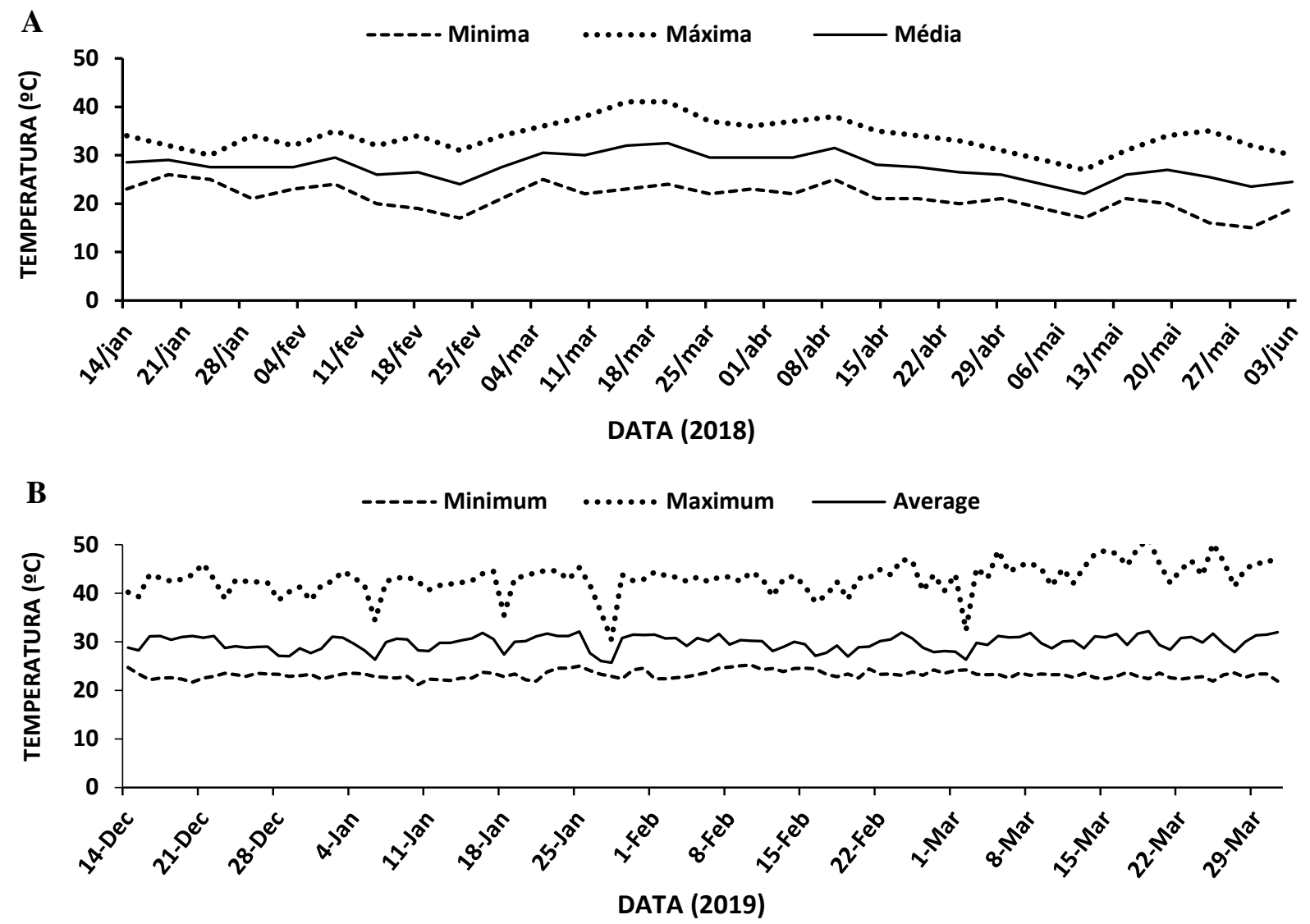

A semeadura foi realizada a $5,0 \mathrm{~cm}$ de profundidade em quantidade suficiente para garantir a emergência de aproximadamente três plântulas. Logo após a emergência realizou-se o desbaste de forma a permanecer apenas uma plântula por vaso. Utilizou-se sementes da cultivar TMG 47 B2RF, a qual não apresenta gene de resistência ao 2,4-D.

Foi adotado 0 delineamento experimental inteiramente casualizado, com sete repetições no qual cada vaso foi considerado como uma unidade experimental. Os tratamentos foram compostos por nove subdoses do herbicida 2,4-D formulação sal colina, que foram: 0 (testemunha); 0,4275; 0,855; 1,71; 3,42; 8,55; 17,$1 ; 34,2$ e $68,4 \mathrm{~g}$ ea ha ${ }^{-1}$. As pulverizações do herbicida foram efetuadas em dois estádios fenológicos distintos do algodoeiro, sendo V4 ou B4.

A aplicação das diferentes subdoses do herbicida 2,4-D sal colina foi realizada quando pelo menos $50 \%$ das plantas estavam no estádio 
fenológico correspondente ao objeto de estudo, com pulverizador de pesquisa pressurizado a $\mathrm{CO}_{2}$ contendo barra de pulverização munida por quatro pontas com indução de ar do tipo leque, modelo AIDA 110015, espaçadas de $0,5 \mathrm{~m}$ entre $\mathrm{si}$, com distância de $0,5 \mathrm{~m}$ do alvo e calibrada a $1,8 \mathrm{kgf} \mathrm{cm}^{-2}$ de pressão, de modo a se obter um consumo de calda equivalente a $150 \mathrm{~L} \mathrm{ha}^{-1}$.

O efeito dos tratamentos foi avaliado observando-se os sintomas visuais de injúria aos 3,7 e 14 dias após a aplicação (DAA), atribuindo valores entre 0 (nenhuma injúria observada) e $100 \%$ (morte das plantas), buscando estabelecer comparativo entre os tratamentos herbicidas e a testemunha sem aplicação das subdoses de 2,4D. Os valores foram ajustados ao modelo de regressão quadrática pelo programa Origin 8.5.1 SR1. Para a escolha do modelo de regressão, foi considerado o maior valor do coeficiente de determinação $\left(R^{2}\right)$ a $p \leq 0,05$ de acordo com o teste $F$, respeitando-se a resposta biológica.

As avaliações da cinética de emissão da fluorescência máxima da clorofila " $\alpha$ " também foram realizadas aos 3, 7 e 14 DAA, com o auxílio de um fluorômetro portátil, marca Handheld chlorophyll fluorometer, modelo OS30p+, para determinar a eficiência fotoquímica do fotossistema II $(F v / F m)$. As avaliações foram realizadas nas folhas completamente expandidas que representavam 0 estádio fenológico estudado com duas repetições por leitura, nas primeiras horas da manhã (entre 05:00 e 06:00 horas), a fim de garantir a adaptação ao escuro pelas folhas. Os valores obtidos foram analisados pelo teste $\mathrm{F}$ e os efeitos dos tratamentos foram comparados pelo teste de Scott-Knott a $5 \%$ de probabilidade utilizando-se o programa estatístico Rbio (BHERING, 2017).

Os dados de injúria visual (\%) e (Fv/Fm), ambos aos 3, 7 e 14 DAA, também foram submetidos à correlação de Pearson utilizando-se o programa estatístico Rbio (BHERING, 2017).

\section{Resultados e Discussão}

Observa-se correlação negativa e significativa entre a injúria visual (\%) e a eficiência quântica do fotossistema II ( Fv/Fm) aos 3, 7 e 14 DAA de subdoses de 2,4-D sal colina em algodoeiro nos estádios V4 e B4 para ambos os anos de condução do experimento (Tabela 1). Os valores negativos de correlação indicam que quando uma determinada variável " $x$ " aumenta, a variável correlacionada " $y$ " diminui (PARANHOS et al., 2014). Por conta disso, os resultados dessa pesquisa indicam que à medida que o percentual de injúria visual aumenta, em consequência da aplicação de maiores subdoses do herbicida, a variável $\mathrm{Fv} / \mathrm{Fm}$ diminui, demonstrando assim danos significativos ao aparato fotoquímico das plantas de algodoeiro.

Tabela 1. Estimativas dos coeficientes de correlação de Pearson entre a injúria visual (\%) e a eficiência quântica do fotossistema II $(\mathrm{Fv} / \mathrm{Fm})$ aos 3, 7 e 14 DAA de subdoses de 2,4-D sal colina em plantas de algodoeiro nos estádios V4 e B4 nos anos 2018 e 2019.

\begin{tabular}{lccc}
\hline \multicolumn{4}{c}{ Correlação: Injúria visual (\%) $\times \mathrm{Fv} / \mathrm{Fm}$} \\
\hline \multirow{2}{*}{ Ano } & \multicolumn{3}{c}{ Estádio V4 } \\
\cline { 2 - 4 } & 3 DAA & 7 DAA & 14 DAA \\
\hline 2018 & $-0,4082^{* *}$ & $-0,4676^{* *}$ & $-0,8041^{* *}$ \\
2019 & $-0,4378^{* *}$ & $-0,4462^{* *}$ & $-0,5386^{* *}$ \\
\hline \multirow{2}{*}{ Ano } & \multicolumn{3}{c}{ Estádio B4 } \\
\cline { 2 - 4 } & 3 DAA & 7 DAA & 14 DAA \\
\hline \multirow{2}{*}{2018} & $-0,4373^{* *}$ & $-0,7018^{* *}$ & $-0,7853^{* *}$ \\
2019 & $-0,5289^{* *}$ & $-0,7834^{* *}$ & $-0,6899^{* *}$ \\
\hline
\end{tabular}

** Significativo a $1 \%$ de probabilidade.

A classificação de intensidade da correlação é considerada fraca quando os valores de $r$ se encontram entre 0,20 e 0,50 , forte entre os valores de 0,50 e 0,70 e muito forte entre 0,70 e 1,0 (KOZAK, 2009), indicando que quanto mais próximo de 1 (independente do sinal) maior é o grau de dependência estatística linear entre as variáveis e quanto mais próximo de zero, menor é a força dessa relação (FIGUEIREDO FILHO; SILVA JÚNIOR, 2009).

Desta forma, foi possível observar correlação negativa de intensidade fraca entre a injúria visual (\%) e a eficiência quântica do fotossistema II (FV/Fm) aos 3 e 7 DAA de subdoses de 2,4-D sal colina em plantas de algodoeiro no estádio V4, independente do ano de condução. Todavia, a intensidade aumentou para valores classificados entre forte e muito forte aos 14 DAA, inferindo que nesse período houve diminuição mais intensa dos valores de $\mathrm{Fv} / \mathrm{Fm}$ devido ao aumento das subdoses de 2,4-D que ocasionaram maiores incrementos aos valores percentuais de injúria visual. No estádio B4 do algodoeiro, a correlação pode ser classificada variando entre fraca e forte aos 3 DAA e variando entre forte e muito forte para os períodos 7 e 14 DAA do herbicida.

Os efeitos visuais de injúria (\%) aos 3, 7 e 14 DAA do herbicida 2,4-D sal colina no estádio V4 do algodoeiro apresentaram comportamento 
quadrático e ascendente, com valores inferiores a $10 \%$ para subdoses menores que $3,42 \mathrm{~g}$ ea $\mathrm{ha}^{-1}$, chegando a aproximadamente $70 \%$ de injúria quando aplicado $68,4 \mathrm{~g}$ ea $\mathrm{ha}^{-1}$ do herbicida aos 14 DAA, em ambos anos de condução do experimento (Figura 2).

Nota-se semelhança no comportamento das linhas de tendência dos valores de injúria visual dos anos de 2018 e 2019 e por conta da intensa mudança de direção das curvas, evidencia-se que as subdoses superiores a 3,42 g ea $\mathrm{ha}^{-1}$ provocaram os efeitos visuais mais severos às plantas de algodoeiro (Figura 2). Salienta-se que as principais injúrias observadas no estádio V4 foram epinastia dos ramos e enrugamento do ápice caulinar e das folhas jovens, principalmente nas subdoses mais elevadas.

Figura 2. Injuria visual (\%) aos 3, 7 e 14 DAA provocada por subdoses do herbicida 2,4-D sal colina aplicadas no estádio V4 de plantas de algodoeiro nos anos 2018 (A) e 2019 (B). ** Significativo $(p \leq 0,01)$.

A

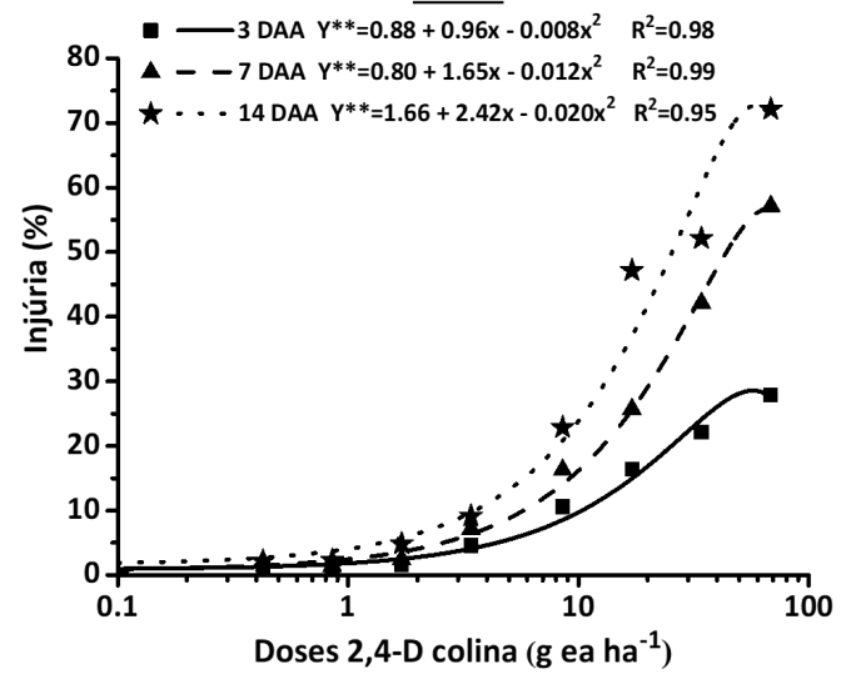

Destaca-se que aos 14 DAA do herbicida, níveis de injúria superiores a $45 \%$ foram observados quando se aplicou 34,2 $\mathrm{g}^{\mathrm{ea} \mathrm{ha}} \mathrm{ha}^{-1}$. Corroborando esse resultado, Byrd et al. (2016) afirmam que no mesmo período de avaliação, no estádio V4 do algodoeiro, percentuais de injúria superiores a $49 \%$ foram observados para a subdose de $40 \mathrm{~g}$ ea $\mathrm{ha}^{-1}$ de 2,4-D sal amina.

Conforme exposto, um dos principais sintomas causados pela aplicação de subdoses de 2,4-D sal colina em plantas de algodoeiro em estádio V4 foi o enrugamento do ápice caulinar e das folhas jovens. Segundo Constantin et al. (2007), esse sintoma, também conhecido como "pata de rã", é descrito como típico de intoxicação por 2,4-D que ocorre principalmente nas folhas novas que se desenvolvem após a ocorrência da contaminação, culminando em perda de área fotossintética.

Constatou-se que a variável $\mathrm{Fv} / \mathrm{Fm}$, que avalia a eficiência do aparato fotossintético do

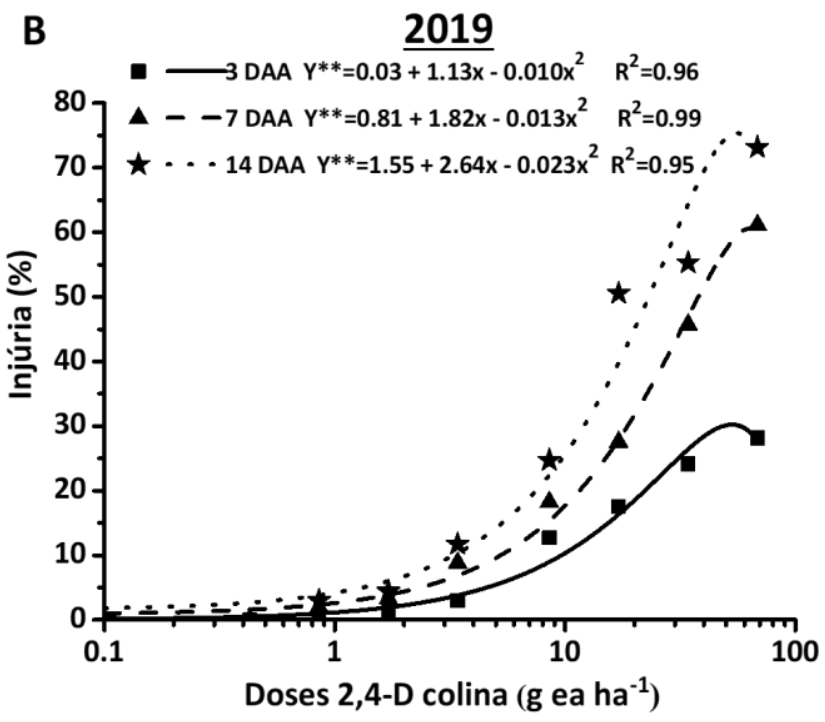

algodoeiro, foi afetada pela aplicação de subdoses de 2,4-D sal colina no estádio V4 independente do ano avaliado, mostrando que algumas subdoses ocasionaram danos ao aparato fotoquímico e nas características da fluorescência da clorofila $\alpha$ do algodoeiro (Tabela 2).

Para o ano de 2018, verifica-se que aos 3 e 7 DAA foi possível observar diferença significativa entre a testemunha e todas as subdoses do herbicida. Todavia, houve aumento nos valores de eficiência quântica do fotossistema II aos 14 DAA para as subdoses 0,$4275 ; 0,855 ; 1,71$ e 3,42 $\mathrm{g}_{\text {ea }} \mathrm{ha}^{-1}$, não sendo observadas assim, diferenças estatísticas entre essas subdoses e a testemunha sem aplicação do herbicida nesse período. Em contrapartida, não houve diferença significativa entre as subdoses 0,$4275 ; 0,855 ; 1,71$ e 3,42 e a testemunha aos 3 , 7 e 14 DAA do herbicida no ano de 2019 (Tabela 2). 
Tabela 2. Eficiência quântica do fotossistema II $(F v / F m)$ de algodoeiro submetido a aplicações de subdoses de 2,4-D sal colina no estádio V4.

\begin{tabular}{|c|c|c|c|}
\hline \multirow{2}{*}{$\begin{array}{c}\text { Doses } \\
\left(\text { g ea ha }^{-1}\right)\end{array}$} & \multicolumn{3}{|c|}{$\mathrm{Fv} / F m(2018)$} \\
\hline & 3 DAA & 7 DAA & 14 DAA \\
\hline 0 & $0,7834 a$ & $0,7841 \mathrm{a}$ & $0,7850 \mathrm{a}$ \\
\hline 0,4275 & $0,7293 \mathrm{~b}$ & $0,7554 \mathrm{~b}$ & $0,7709 a$ \\
\hline 0,855 & $0,7301 \mathrm{~b}$ & $0,7600 \mathrm{~b}$ & $0,7713 a$ \\
\hline 1,71 & $0,7320 \mathrm{~b}$ & $0,7546 \mathrm{~b}$ & $0,7693 \mathrm{a}$ \\
\hline 3,42 & $0,7358 \mathrm{~b}$ & $0,7565 b$ & $0,7660 \mathrm{a}$ \\
\hline 8,55 & $0,7183 \mathrm{~b}$ & $0,7163 \mathrm{c}$ & $0,7466 \mathrm{~b}$ \\
\hline 17,1 & $0,7251 b$ & $0,7393 \mathrm{c}$ & $0,7306 \mathrm{~b}$ \\
\hline 34,2 & $0,7297 \mathrm{~b}$ & $0,7160 \mathrm{c}$ & $0,7303 \mathrm{~b}$ \\
\hline 68,4 & $0,7067 \mathrm{~b}$ & $0,7289 c$ & $0,6989 \mathrm{c}$ \\
\hline Média Geral & 0,7346 & 0,7471 & 0,7520 \\
\hline F Doses & $7,07 * *$ & $9,24 * *$ & $18,78^{* *}$ \\
\hline d.m.s. & 0,0242 & 0,0220 & 0,0181 \\
\hline CV (\%) & 3,07 & 2,75 & 2,24 \\
\hline Doses & \multicolumn{3}{|c|}{ Fv/Fm (2019) } \\
\hline$\left(\right.$ g ea ha $\left.^{-1}\right)$ & 3 DAA & $7 \mathrm{DAA}$ & 14 DAA \\
\hline 0 & $0.7821 \mathrm{a}$ & $0.7816 \mathrm{a}$ & $0.7833 \mathrm{a}$ \\
\hline 0,4275 & $0.7431 a$ & $0.7584 a$ & $0.7661 \mathrm{a}$ \\
\hline 0,855 & $0.7377 a$ & $0.7521 \mathrm{a}$ & $0.7641 \mathrm{a}$ \\
\hline 1,71 & $0.7520 \mathrm{a}$ & $0.7606 \mathrm{a}$ & $0.7693 \mathrm{a}$ \\
\hline 3,42 & $0.7483 \mathrm{a}$ & $0.7317 \mathrm{a}$ & $0.7454 \mathrm{a}$ \\
\hline 8,55 & $0.7041 b$ & $0.6877 \mathrm{~b}$ & $0.7056 \mathrm{~b}$ \\
\hline 17,1 & $0.6904 \mathrm{~b}$ & $0.6954 \mathrm{~b}$ & $0.6999 \mathrm{~b}$ \\
\hline 34,2 & $0.6967 \mathrm{~b}$ & $0.6901 \mathrm{~b}$ & $0.6899 \mathrm{~b}$ \\
\hline 68,4 & $0.7091 \mathrm{~b}$ & $0.6899 \mathrm{~b}$ & $0.6781 \mathrm{~b}$ \\
\hline Média Geral & 0,7293 & 0,7275 & 0,7335 \\
\hline F Doses & $2,45^{*}$ & $2,75^{*}$ & $3,22 * *$ \\
\hline d.m.s. & 0,0555 & 0,0634 & 0,0631 \\
\hline CV (\%) & 7,10 & 8,13 & 8,03 \\
\hline
\end{tabular}

** Significativo a $1 \%$ de probabilidade. ${ }^{*}$ Significativo a $5 \%$ de probabilidade. Médias seguidas de mesma letra na coluna não diferem estatisticamente entre si pelo teste de Scott-Knott ao nível de 5\% de probabilidade.

Segundo Yusuf et al. (2010) a análise da fluorescência da clorofila $\alpha$ é capaz de detectar com segurança e confiabilidade efeitos de estresse e injúrias no processo fotossintético causados por diversos fatores. As reduções na cinética de emissão de fluorescência da clorofila $\alpha$ em algodoeiro, observadas nos tratamentos superiores a 3,42 $\mathrm{g}$ ea ha ${ }^{-1}$, são resultados de frequentes modificações na atividade fotossintética, principalmente com relação a eficiência quântica do transporte de elétrons através do fotossistema II em folhas. Sabe-se que plantas sob ausência de estresse apresentam potencial de rendimento quântico $(F V / F m)$ na faixa entre 0,75 e 0,85 (CORRÊA; ALVES, 2010). Portanto, valores abaixo de 0,75 podem demonstrar que as folhas sofreram danos fotoinibitórios e por conta disso, infere-se que a aplicação de subdoses superiores a $3,42 \mathrm{~g}$ ea ha ${ }^{-1}$ aos 14 DAA promoveram distúrbios ao aparato fotossintético das plantas de algodoeiro, independente do ano de avaliações.

Destaca-se que nesse estudo, para a subdose de $68,4 \mathrm{~g}$ ea ha ${ }^{-1}$ no ano de 2018 , e para as subdoses superiores à $8,55 \mathrm{~g}$ ea ha ${ }^{-1} \mathrm{em} 2019$, ambos aos 14 DAA, foi possível observar valores de $\mathrm{FV} / \mathrm{Fm}$ inferiores a 0,70 , indicando que a aplicação dessas subdoses foram capazes de reduzir de forma mais intensa a eficiência fotossintética do algodoeiro em estádio V4.

Os valores de injúria visual (\%) observados aos 3, 7 e 14 DAA do herbicida 2,4-D 
sal colina no estádio B4 do algodoeiro foram menores que $15 \%$ quando aplicadas subdoses inferiores a $8,55 \mathrm{~g}$ ea $\mathrm{ha}^{-1}$, chegando a aproximadamente $62 \%$ de injúria quando aplicado $68,4 \mathrm{~g}$ ea ha ${ }^{-1}$ do herbicida aos 14 DAA, com curvas com comportamento quadrático e ascendente para os respectivos anos de estudo deste experimento (Figura 3).

Figura 3. Injúria visual (\%) aos 3, 7 e 14 DAA provocada por subdoses do herbicida 2,4-D sal colina aplicadas no estádio B4 de plantas de algodoeiro nos anos 2018 (A) e 2019 (B). ** Significativo ( $p \leq 0,01)$.

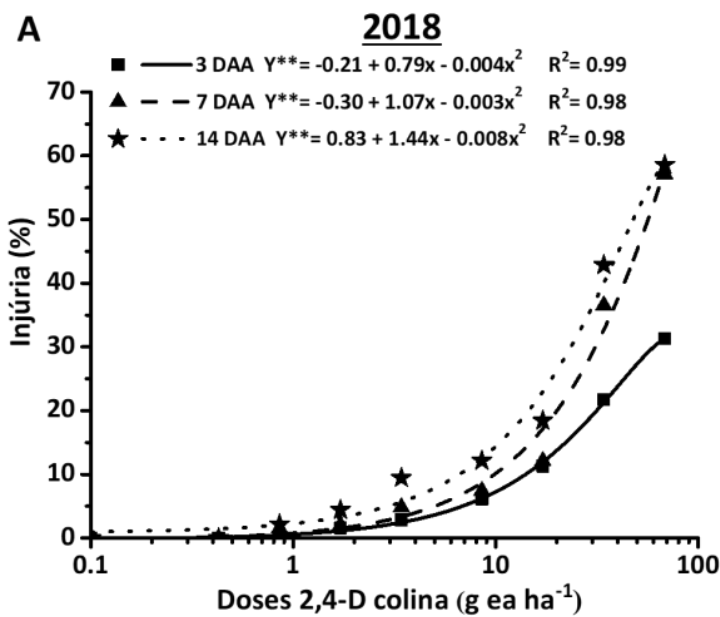

As principais injúrias visuais observadas nesse estádio foram epinastia do pecíolo das folhas, manchas foliares arroxeadas, ressecamento foliar e morte do ápice caulinar, principalmente em doses mais elevadas. Segundo Yamashita et al. (2013), a fitotoxicidade do 2,4-D pode variar nas plantas desde uma leve epinastia nas folhas, seguida pela deformação, até a morte da planta.

Os dados de injúria mostram que plantas de algodoeiro apresentam maior sensibilidade ao herbicida 2,4-D sal colina quando contaminações ocorrem nos primeiros estádios de desenvolvimento da cultura. Nota-se por exemplo que, quando aplicado $8,55 \mathrm{~g}$ ea ha ${ }^{-1}$ do herbicida em estádio V4 a injúria visual foi estimada em aproximadamente $22 \%$ aos 14 DAA (Figura 2), enquanto que para o estádio B4 este valor não ultrapassou $15 \%$ para a referida subdose (Figura 3).

Porém, independente do estádio fenológico, os efeitos de injúria foram mais perceptíveis conforme aumentou-se as subdoses do herbicida. Byrd et al. (2016) comentam que, como tem sido amplamente conhecido desde a descoberta do 2,4-D, o algodoeiro é extremamente sensível a este herbicida principalmente durante os estádios vegetativos, sendo que a partir dos estádios de pré-

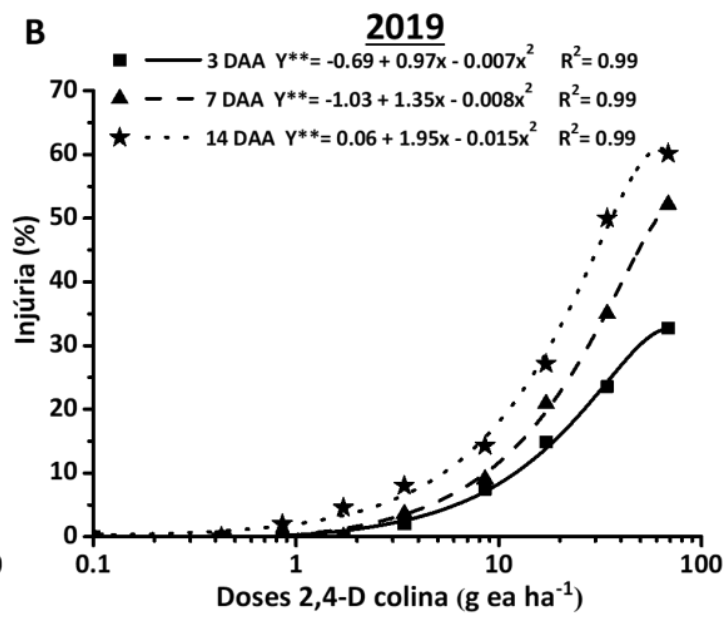

florescimento (botões florais) essa sensibilidade cai devido as folhas estarem mais desenvolvidas.

Por ser um herbicida da classe dos mimetizadores de auxinas e devido à característica de serem ácidos fracos, a habilidade do herbicida 2,4-D em penetrar a membrana plasmática é dependente do $\mathrm{pH}$ das plantas. $\mathrm{O} \mathrm{pH}$ apoplástico em plantas é aproximadamente 5,5 . Nesse $\mathrm{pH}$, o equilíbrio das moléculas de auxina é calculado para ser aproximadamente $83 \%$ dissociado e $17 \%$ não dissociado (ou próton-associado). Nesse caso, a carga negativa do grupo carboxílico dissociado da molécula irá impedi-lo de atravessar a membrana sendo que apenas as moléculas não dissociadas poderão atravessar a membrana plasmática por difusão passiva, sem a necessidade da assistência de proteínas transportadoras (ZAŽímALOVÁ et al., 2010).

O citoplasma das células vegetais, por sua vez, apresenta $\mathrm{pH}$ próximo a 7,0 fazendo com que o equilíbrio das moléculas de auxina se desloque quase que inteiramente para as formas dissociadas ou aniônicas. Como as auxinas aniônicas não conseguem se difundir através da membrana plasmática as mesmas ficam aprisionadas dentro das células (ZAŽímALOVÁ et al., 2010). Acrescido a isso, plantas de algodoeiro na fase inicial de crescimento até o sexto estádio foliar (V6) são mais sensíveis a exposições de 2,4- 
D, visto que a sensibilidade pode ser aumentada devido ao reduzido desenvolvimento da planta e a falta de uma cutícula completamente desenvolvida, interferindo diretamente na difusão passiva do herbicida ocasionando danos às paredes celulares das folhas (SMITH et al., 2017).

Os resultados encontrados nesse estudo corroboram com Egan et al. (2014), que afirmam que durante os estádios de botões florais (préflorescimento), o algodoeiro apresentou baixa sensibilidade às exposições de subdoses do herbicida 2,4-D. Todavia, Everitt e Keeling (2009) acrescentam que, mesmo que a injúria no início da temporada tenha sido consistente, o hábito de crescimento indeterminado do algodoeiro permite uma compensação considerável para o estresse dependendo das condições ambientais, não sendo assim bom indicador de efeitos sobre o comportamento das plantas.

A variável $\mathrm{Fv} / \mathrm{Fm}$ foi afetada pela aplicação de subdoses de 2,4-D sal colina superiores a 1,71 $\mathrm{g}$ ea $\mathrm{ha}^{-1}$ no estádio B4 do algodoeiro, indicando que essas subdoses ocasionaram danos ao aparato fotoquímico e nas características da fluorescência da clorofila $\alpha$ do algodoeiro em ambos os anos de condução do experimento. Para o ano de 2018, não foi possível observar diferença significativa entre a testemunha e as subdoses 0,$4275 ; 0,855 ; 1,71 \mathrm{e}$ $3,42 \mathrm{~g}$ ea $\mathrm{ha}^{-1}$ aos 3,7 e 14 DAA. Esse mesmo comportamento também foi observado aos 3 e 7 DAA do herbicida no ano de 2019, porém a subdose $3,42 \mathrm{~g}$ ea $\mathrm{ha}^{-1}$ diferenciou-se da testemunha aos 14 DAA (Tabela 3).

Tabela 3. Eficiência quântica do fotossistema II $(F v / F m)$ de algodoeiro submetido a aplicações de subdoses de 2,4-D sal colina no estádio B4.

\begin{tabular}{|c|c|c|c|}
\hline \multirow{2}{*}{$\begin{array}{c}\text { Doses } \\
\left(\text { g ea ha }^{-1}\right)\end{array}$} & \multicolumn{3}{|c|}{ Fv/Fm (2018) } \\
\hline & 3 DAA & 7 DAA & 14 DAA \\
\hline 0 & $0,7661 \mathrm{a}$ & $0,7617 \mathrm{a}$ & $0,7619 a$ \\
\hline 0,4275 & $0,7554 a$ & $0,7500 \mathrm{a}$ & $0,7660 \mathrm{a}$ \\
\hline 0,855 & 0,7649 a & 0,7559 a & $0,7549 a$ \\
\hline 1,71 & $0,7629 a$ & $0,7501 \mathrm{a}$ & $0,7517 a$ \\
\hline 3,42 & $0,7407 a$ & 0,7366 a & $0,7131 \mathrm{a}$ \\
\hline 8,55 & $0,7083 \mathrm{~b}$ & $0,6440 \mathrm{~b}$ & $0,6200 \mathrm{~b}$ \\
\hline 17,1 & $0,7150 \mathrm{~b}$ & $0,5810 \mathrm{c}$ & $0,5299 c$ \\
\hline 34,2 & $0,7184 \mathrm{~b}$ & $0,4740 \mathrm{~d}$ & $0,4141 d$ \\
\hline 68,4 & $0,6061 \mathrm{c}$ & $0,3750 \mathrm{e}$ & 0,1604 e \\
\hline Média Geral & 0,7264 & 0,6464 & 0,6080 \\
\hline F Doses & $9,96 * *$ & $42,32 * *$ & $113,38 * *$ \\
\hline d.m.s. & 0,0454 & 0,0617 & 0,0554 \\
\hline CV (\%) & 5,83 & 8,91 & 8,5 \\
\hline \multirow{2}{*}{$\begin{array}{c}\text { Doses } \\
\left(\mathrm{g}^{2} \text { ea ha }{ }^{-1}\right)\end{array}$} & \multicolumn{3}{|c|}{$\mathrm{Fv} / \mathrm{Fm}$ (2019) } \\
\hline & 3 DAA & 7 DAA & 14 DAA \\
\hline 0 & $0.7707 a$ & $0.7743 \mathrm{a}$ & $0.7724 a$ \\
\hline 0,4275 & $0.7676 a$ & $0.7653 \mathrm{a}$ & $0.7703 \mathrm{a}$ \\
\hline 0,855 & $0.7601 \mathrm{a}$ & $0.7631 \mathrm{a}$ & $0.7774 a$ \\
\hline 1,71 & $0.7563 \mathrm{a}$ & $0.7641 \mathrm{a}$ & $0.7704 \mathrm{a}$ \\
\hline 3,42 & $0.7471 \mathrm{a}$ & $0.7246 a$ & $0.6629 \mathrm{~b}$ \\
\hline 8,55 & $0.7247 a$ & $0.7007 \mathrm{~b}$ & $0.6839 \mathrm{~b}$ \\
\hline 17,1 & $0.6834 \mathrm{~b}$ & $0.6767 \mathrm{~b}$ & $0.6599 \mathrm{~b}$ \\
\hline 34,2 & $0.6596 \mathrm{~b}$ & $0.6369 \mathrm{~b}$ & $0.5794 \mathrm{~b}$ \\
\hline 68,4 & $0.6284 \mathrm{~b}$ & $0.4976 \mathrm{c}$ & $0.2779 c$ \\
\hline Média Geral & 0,7231 & 0,7003 & 0,6616 \\
\hline F Doses & $12,59 * *$ & $7,63 * *$ & $27,35 * *$ \\
\hline d.m.s. & 0,0423 & 0,0918 & 0,0865 \\
\hline CV (\%) & 5,46 & 12,23 & 12,21 \\
\hline
\end{tabular}

NS - Não significativo; ${ }^{* *}$ Significativo a $1 \%$ de probabilidade. Médias seguidas de mesma letra na coluna não diferem estatisticamente entre si pelo teste de Scott-Knott ao nível de 5\% de probabilidade. 
Segundo Silva et al. (2014) a eficiência quântica do fotossistema II pode ser um bom indicador de danos promovidos pelos herbicidas, mesmo em doses baixas, visto que os valores entre 0,75 e 0,85 em plantas saudáveis são considerados normais. Por conta disso, infere-se que há uma maior segurança em relação às subdoses 0,$4275 ; 0,855$ e $1,71 \mathrm{~g}^{\text {ea }} \mathrm{ha}^{-1}$ do herbicida 2,4-D sal colina em caso de contaminação durante o estádio B4, visto que neste trabalho observou-se que os valores de $\mathrm{Fv} / \mathrm{Fm}$ para essas subdoses estiveram acima de 0,75 durante todo o período experimental.

Conforme apresentado anteriormente, os dados de injúria nesta pesquisa mostram que plantas de algodoeiro em estádio inicial de desenvolvimento apresentam maior sensibilidade ao herbicida 2,4-D sal colina. Todavia, comparando-se a variável $\mathrm{Fv} / \mathrm{Fm}$ entre os estádios fenológicos, observa-se que quando as subdoses do herbicida foram aplicadas no estádio B4 do algodoeiro, houve elevada redução da eficiência quântica do fotossistema II (Tabela 3) quando comparado ao estádio V4 (Tabela 2).

Como também foi citado, uma das principais injúrias visuais observadas após a aplicação do herbicida no estádio B4 foi o aparecimento de manchas foliares arroxeadas. Esse fenômeno, que ocorre normalmente em estádios fenológicos mais avançados, é descrito como "avermelhamento das folhas" e pode ser associado aos distúrbios fisiológicos resultantes de vários fatores bióticos e abióticos que causam estresse as plantas, resultando em intensa síntese e acúmulo de antocianina (HOSAMANI et al., 2017; AMBATI, 2017). As antocianinas são compostos fenólicos pertencentes ao grupo dos flavonoides que se encontram largamente distribuídos na natureza sendo pigmentos vegetais responsáveis pelas cores vermelho, azul e violeta que podem aparecer em flores, frutos, folhas, caules e raízes de plantas (BUTELLI et al., 2017).

Pagare e Durge (2011) acrescentam que existe relação inversamente proporcional entre os teores de clorofila e de antocianina nas folhas de algodoeiro, uma vez que severas reduções do teor de clorofila são observadas em folhas com maiores acúmulos de antocianina, culminando em reduções na atividade fotossintética das plantas.

Dentre os diversos parâmetros de fluorescência da clorofila que podem ser medidos, como por exemplo os coeficientes de extinção fotoquímico $\left(q^{P}\right), \quad$ a eficiência fotoquímica efetiva $\left(\mathrm{Fv}^{\prime} / \mathrm{Fm}^{\prime}\right)$ e a taxa de transporte de elétrons (ETR), o máximo rendimento quântico fotoquímico do fotossistema II ( $F v / F m)$, frequentemente avaliado pela máxima taxa de fluorescência da clorofila $\alpha$, tem sido amplamente utilizado para comparar tecidos saudáveis e danificados (ROUSSEAU et al., 2013).

Velikova et al. (2002), estudando os efeitos do avermelhamento das folhas de algodoeiro na atividade funcional do aparato fotossintético das plantas, afirmam que quanto mais intensa a coloração avermelhada nas folhas, menor é a relação $\mathrm{Fv} / \mathrm{Fm}$, com reduções que podem variar entre 75 e $90 \%$ em relação a testemunha. Por conta disso, supõe-se que esse sintoma causado pela aplicação de subdoses do herbicida 2,4-D sal colina tenha sido o principal fator que ocasionou reduções ao aparato fotossintético do algodoeiro em estádio B4, uma vez observadas reduções de até $79 \%$ em relação a testemunha quando aplicado $68,4 \mathrm{~g}$ ea ha ${ }^{-1}$.

\section{Conclusões}

A correlação entre a injúria visual (\%) e a eficiência quântica do fotossistema II (Fv/Fm) aos 3, 7 e 14 DAA de subdoses de 2,4-D sal colina em algodoeiro, nos estádios V4 e B4, para ambos os anos de condução, é negativa e significativa.

Plantas de algodoeiro apresentam maior sensibilidade ao herbicida 2,4-D sal colina quando contaminações ocorrem nos primeiros estádios de desenvolvimento da cultura.

A variável $F v / F m$ não foi afetada pela aplicação de subdoses inferiores a 3,42 $\mathrm{g}$ ea ha ${ }^{-1}$ de 2,4-D sal colina no estádio V4 e inferiores a $1,71 \mathrm{~g}$ ea ha ${ }^{-1}$ no estádio B4 do algodoeiro.

\section{Agradecimentos}

Os autores agradecem a Coordenação de Aperfeiçoamento de Pessoal de Nível Superior (CAPES) e CORTEVA Agriscience por apoiar esse estudo.

\section{Referências}

AMBATI, R. R. Leaf reddening in bt hybrid cotton. Agricultural Research \& Technology: Open Access Journal, v. 3, n. 4, p. 01-04, 2017. https://doi.org/10.19080/ARTOAJ.2017.03.55561 8 
BHERING, L. L. RBIO: A tool for biometric and statistical analysis using the $\mathrm{R}$ Platform. Crop Breeding and Applied Biotechnology, v. 17, n. 2, p.187-190, 2017. http://dx.doi.org/10.1590/1984$\underline{70332017 \mathrm{v} 17 \mathrm{n} 2 \mathrm{~s} 29}$

BUONASERA, K.; LAMBREVA, M.; REA, G.; TOULOUPAKIS, E.; GIARDI, M. T. Technological applications of chlorophyll a fluorescence for the assessment of environmental pollutants. Analytical and Bioanalytical Chemistry, v. 4, n.401, p.1139-1151, 2011. https://doi.org/10.1007/s00216-011-5166-1

BUTELLI, E.; GARCIA-LOR, A.; LICCIARDELLO, C.; CASAS, G.; HILL, L.; RECUPERO, G. F.; KEREMANE, M. L.; RAMADUGU, C.; KRUEGER, R.; XU, Q.; DENG, X.; FANCIULLINO, A. N.; FROELICHER, Y.; NAVARRO, L.; MARTIN, C. Changes in anthocyanin production during domestication of Citrus. Plant physiology, v. 173, n. 4, p. 2225-2242, 2017. https://doi.org/10.1104/pp.16.01701

BYRD, S. A.; COLLINS, G. D.; CULPEPPER, A. S.; DODDS, D. M.; EDMISTEN, K. L.; WRIGHT, D. L.; MORGAN, G. D.; BAUMANN, P. A.; DOTRAY, P. A.; MANUCHEHRI, M. R.; JONES, A.; GREY, T. L.; WEBSTER, T. M.; DAVIS, J. W.; WHITAKER, J. R.; ROBERTS, P. M.; SNIDER, J. L.; PORTER, W. M. Cotton stage of growth determines sensitivity to 2, 4-D. Weed technology, v. 30, n. 3, p. 601-610, 2016. https://doi.org/10.1614/WT-D-15-00191.1

CONSTANTIN, J.; OLIVEIRA JÚNIOR, R. S.; FAGLIARI, J. R.; PAGLIARI, P. H.; ARANTES, J. G.; CAVALIERI, S. D.; FRAMESQUI, V. P.; GONÇALVES, D. Efeito de subdoses de 2,4-D na produtividade do algodão e suscetibilidade da cultura em função de seu estádio de desenvolvimento. Engenharia Agrícola, v. 27, n. Esp., p. 24-29, $2007 . \quad$ http://dx.doi.org/10.1590/S0100$\underline{69162007000200004}$

CORRÊA, M. J. P.; ALVES, P. L. C. A. Efeitos da aplicação de herbicidas sobre a eficiência fotoquímica em plantas de soja convencional e geneticamente modificada. Ciência e Agrotecnologia, v. 34, n. 5, p. 1136-1145, 2010. http://dx.doi.org/10.1590/S1413$\underline{70542010000500009}$
CRUZ, M. D.; SIQUEIRA, D. D.; SALOMÃO, L. C. C.; CECON, P. R. Fluorescência da clorofila $\alpha$ em folhas de tangerineira 'Ponkan' e limeira ácida 'Tahiti' submetidas ao estresse hídrico. Revista Brasileira de Fruticultura, v. 31, n. 3, p. 896-901, $2009 . \quad$ https://doi.org/10.1590/S010029452009000300037

EGAN, J. F.; BARLOW, K. M.; MORTENSEN, D. A. A meta-analysis on the effects of 2,4-D and dicamba drift on soybean and cotton. Weed Sciences, v. 62, n. 1, p. 193-206, 2014. https://doi.org/10.1614/WS-D-13-00025.1

EVERITT, J. D.; KEELING, J. W. Cotton growth and yield response to simulated 2, 4-D and dicamba drift. Weed Technology, v. 23, n. 4, p. 503-506, 2009. https://doi.org/10.1614/WT-08-061.1

FERREIRA, E. A.; MATOS, C. D. C.; BARBOSA, E. A.; SILVA, D. V.; SANTOS, J. B.; PEREIRA, G. A. M.; FARIA, A. T.; SILVA, C. T. Respostas fisiológicas da mandioca à aplicação de herbicidas. Semina: Ciências Agrárias, v. 36, n. 2, p. 645-656, 2015. https://doi.org/10.5433/1679-

$\underline{0359.2015 v 36 n 2 p 645}$

FIGUEIREDO FILHO, D. B.; SILVA JÚNIOR, J. A. D. Desvendando os mistérios do Coeficiente de Correlação de Pearson (r). Revista Política Hoje, v. 18, n. 1, p. 116-146, 2009.

GONÇALVES, E. R.; FERREIRA, V. M.; SILVA, J. V.; ENDRES, L.; BARBOSA, T. P.; DUARTE, W. G. Trocas gasosas e fluorescência da clorofila $\alpha$ em variedades de cana-de-açúcar submetidas à deficiência hídrica. Revista Brasileira de Engenharia Agrícola e Ambiental, v. 14, n. 4, p. 378-86, 2010. https://doi.org/10.1590/S141543662010000400006

HOSAMANI, V.; CHITTAPUR, B. M.; HOSAMANI, V.; HIREMATH, R. Leaf reddening enigma in bt cotton: a review. International Journal of Current Microbiology and Applied Sciences, v. 6, n. 11, p. 3764-3772, 2017. https://doi.org/10.20546/ijcmas.2017.611.441

KOZAK, M. What is strong correlation? Teaching Statistics, v.31, n.3, p.85-86, 2009. https://doi.org/10.1111/i.14679639.2009.00387.x 
MARQUES, R. F.; MARCHI, S. R.; PINHEIRO, G. H.; SOUZA, R. M.; ASSUNÇÃO, H. F.; LÚCIO, F. R. Hormesis of 2, 4-D Choline salt in biometric aspects of cotton. Journal of Agricultural Science, v.11, n.13, p.283-294, 2019. https://doi.org/10.5539/jas.v11n13p283

MICHELOTTO, M. D.; CARREGA, W. C.; GALLI, J. A.; NETTO, J. C.; FINOTO, E. L.; BUSOLI, A. C. Germinação de sementes de algodoeiro provenientes de plantas submetidas a diferentes densidades larvais do curuquerê-do-algodoeiro. Revista Brasileira de Ciências Agrárias (Agrária), v.7, n.4, p.603-607, 2012. https://doi.org/10.5039/agraria.v7i4a1799

PAGARE, G. A.; DURGE, D. V. Pigment analysis studies with reference to leaf reddening in $\mathrm{Bt}$ cotton. International Journal of Plant Sciences, $v$. 6, n. 1, p. 42-44, 2011.

PARANHOS, R.; FIGUEIREDO FILHO, D. B.; ROCHA, E. C.; SILVA JÚNIOR, J. A.; NEVES, J. A. B.; SANTOS, M. L. W. D. Desvendando os mistérios do coeficiente de correlação de Pearson: o retorno. Leviathan, n.8, p.66-95, 2014. https://doi.org/10.11606/issn.22374485.lev.2014.132346

PETERSON, M. A.; MCMASTER, S. A.; RIECHERS, D. E.; SKELTON, J.; STAHLMAN, P. W. 2, 4-D past, present, and future: a review. Weed Technology, v.30, n.2, p.303-345, 2016. https://doi.org/10.1614/WT-D-15-00131.1

RODRIGUES, B. N.; ALMEIDA, F. S. Guia de herbicidas. 6. ed. Londrina, 2011. 694p.

ROUSSEAU, C.; BELIN, E.; BOVE, E.; ROUSSEAU, D.; FABRE, F.; BERRUYER, R.; GUILLAUMĖS, J.; MANCEAU, C.; JACQUES, M.; BOUREAU, T. High throughput quantitative phenotyping of plant resistance using chlorophyll fluorescence image analysis. Plant Methods, v. 9, n. 1, p. 17, 2013. https://doi.org/10.1186/1746-4811-9-17

SILVA, F. B.; COSTA, A. C.; ALVES, R. R. P.; MEGGUER, C. A. Chlorophyll fluorescence as an indicator of cellular damage by glyphosate herbicide in Raphanus sativus L. plants. American Journal of Plant Sciences, v. 5, n. 16, p. 2509, 2014.

http://dx.doi.org/10.4236/ajps.2014.516265
SMITH, H. C.; FERRELL, J. A.; WEBSTER, T. M.; FERNANDEZ, J. V. Cotton response to simulated auxin herbicide drift using standard and ultra-low carrier volumes. Weed Technology, v. 31, n. 1, p. 1-9, 2017. https://doi.org/10.1614/WT-D-1600101.1

SOSNOSKIE, L. M.; CULPEPPER, A. S.; BRAXTON, L. B.; RICHBURG, J. S. Evaluating the volatility of three formulations of 2,4-D when applied in the field. Weed Technology, v. 29, n. 2, p. 177-184, 2015. https://doi.org/10.1614/WT-D-14-00128.1

VELIKOVA, V.; TSONEV, T.; EDREVA, A.; GÜREL, A.; HAKERLERLER, $\mathrm{H}$. Effects of reddening of cotton (Gossypium hirsutum L.) leaves on functional activity of photosynthetic apparatus. Photosynthetica, v. 40, n. 3, p. 449-452, 2002. https://doi.org/10.1023/A:1022695513060

WENDEL, J. F.; BRUBAKER, C. L.; SEELANAN, T. The origin and evolution of Gossypium. In: Physiology of cotton. Dordrecht: Springer, 2010. p.1-18. $\quad$ https://doi.org/10.1007/978-90-4813195-2 1

YAMASHITA, O. M.; ORSI, J. V. N.; RESENDE, D. D.; MENDONÇA, F. S.; CAMPOS, O. R.; MASSAROTO, J. A.; CARVALHO M. A. C.; KOGA, P. S.; PEREZ, W. M.; ALBERGUINI, A. L. Deriva simulada de herbicidas em mudas de Coffea canephora. Scientia Agraria Paranaensis, v. 12, n. 2, p. 148156, 2013. http://dx.doi.org/10.1818/sap.v12i2.5680

YUSUF, M. A.; KUMAR, D.; RAJWANSHI, R.; STRASSER, R. J.; TSIMILLI-MICHAEL, M.; SARIN, N. $B$. Overexpression of $\gamma$-tocopherol methyl transferase gene in transgenic Brassica juncea plants alleviates abiotic stress: physiological and chlorophyll a fluorescence measurements. Biochimica et Biophysica Acta (BBA)Bioenergetics, v. 1797, n. 8, p. 1428-1438, 2010. https://doi.org/10.1016/j.bbabio.2010.02.002

ZAŽíMALOVÁ, E.; MURPHY, A. S.; YANG, H.; HOYEROVÁ, K.; HOŠEK, P. Auxin transportersWhy so many?. Cold Spring Harbor Perspectives in Biology, v.2, n.3, p. 01-14, 2010 https://doi.org/10.1101/cshperspect.a001552 
ZONTA, J. H.; BRANDÃO, Z. N.; MEDEIROS, J. D. C.; SANA, R. S.; SOFIATTI, V. Variabilidade espacial da fertilidade do solo em área cultivada com algodoeiro no Cerrado do Brasil. Revista Brasileira de Engenharia Agrícola e AmbientalAgriambi, v. 18, n. 6, p. 595-602, 2014. https://doi.org/10.1590/S1415$\underline{43662014000600005}$ 